\title{
The Potential of Heliox as a Therapy for Acute Respiratory Distress Syndrome in Adults and Children: A Descriptive Review
}

\author{
Charlotte J.P. Beurskens ${ }^{\mathrm{a}, \mathrm{b}} \quad$ Roelie M. Wösten-van Asperen ${ }^{c} \quad$ Benedikt Preckel $^{\mathrm{a}, \mathrm{d}}$ \\ Nicole P. Juffermans ${ }^{a, b}$ \\ a Laboratory of Experimental Intensive Care and Anaesthesiology, Departments of ${ }^{\mathrm{b}}$ Intensive Care Medicine, ${ }^{\mathrm{C} P a e d i a t r i c}$ \\ Intensive Care and ${ }^{\mathrm{d}}$ Anaesthesiology, Academic Medical Center, University of Amsterdam, Amsterdam, The Netherlands
}

\section{Key Words}

Acute respiratory distress syndrome $\cdot$ Respiratory distress syndrome · Mechanical ventilation · Helium · Heliox .

Intensive care medicine $\cdot$ Paediatric intensive care medicine $\cdot$ Lung injury

\section{Abstract}

Background: In neonatal respiratory distress syndrome (RDS) and acute RDS (ARDS) mechanical ventilation is often necessary to manage hypoxia, whilst protecting the lungs through lower volume ventilation and permissive hypercapnia. Mechanical ventilation can, however, induce or aggravate the lung injury caused by the respiratory distress. Helium, in a gas mixture with oxygen (heliox), has a low density and can reduce the flow in narrow airways and allow for lower driving pressures. Objectives: The aim of this study was to review preclinical and clinical studies of the use of heliox ventilation in acute lung injury associated with respiratory failure. Methods: A systematic search was executed in the PubMed and EMBASE databases, with search terms referring to ARDS or an acute lung injury condition associated with respiratory failure and the corresponding intervention. $\boldsymbol{R e}$ sults: A total of 576 papers were retrieved. After the majority had been excluded 20 papers remained, of which 6 articles described animal models ( 3 paediatric; 3 adult animal models) and 14 were clinical studies, of which 12 described paediatric patient populations and 2 adult patient populations. In both paediatric and adult animal models, heliox improved gas exchange while allowing for less invasive ventilation in a wide variety of models using different ventilation modes. Clinical studies show a reduction in the work of breathing during heliox ventilation, with a concomitant increase in $\mathrm{pH}$ and decrease in $\mathrm{PaCO}_{2}$ levels compared to oxygen ventilation. Conclusions: Although evidence so far is limited, there may be a rationale for heliox ventilation in ARDS as an intervention to improve ventilation and reduce the work of breathing.

(c) 2015 S. Karger AG, Basel

\section{Introduction}

Acute respiratory distress syndrome (ARDS) is a wellknown entity in critically ill patients, with mortality rates of $20 \%$ among paediatric patients and $60 \%$ among the elderly [1-3]. Common features of ARDS are hypoxia and hypercapnia, the latter being due to increased dead space with a concomitant increased work of breathing, which is due to both obstructed airways with increased

\section{KARGER 125}

C 2015 S. Karger AG, Basel

$0025-7931 / 15 / 0892-0166 \$ 39.50 / 0$ 
airway resistance as well as to an increased need for $\mathrm{CO}_{2}$ removal [4-6]. These processes occurring during ARDS frequently warrant mechanical ventilation. In neonates, ARDS is called neonatal RDS and the pathophysiology also includes a surfactant dysfunction [7, 8].

In both ARDS and neonatal RDS, mechanical ventilation is necessary but can induce or aggravate pulmonary damage. Overstretching of alveoli by application of high tidal volumes or high driving pressures and by repetitive opening and closing of the alveoli can all lead to ventilator-induced lung injury and a pro-inflammatory state [7,9-11]. Mechanical and inflammatory processes most likely interact: a mechanically stressed lung may produce an inflammatory reaction. Conversely, inflammation renders the lung susceptible to mechanical stress [12].

It is well recognized that a limited tidal volume ventilation of $6 \mathrm{ml} / \mathrm{kg}$ is beneficial in ARDS [7, 13]. The use of even lower tidal volumes was found to confer additional protection in ARDS and neonatal RDS [7, 14]. In addition to limited tidal volumes, high airway pressures are also linearly associated with mortality $[15,16]$. The application of relatively low plateau pressures $\left(26-27 \mathrm{~cm} \mathrm{H}_{2} \mathrm{O}\right.$ ) can already generate an inflammatory response in the lung [10]. Despite recognition that the intensity of mechanical ventilation influences the outcome of ARDS, application of limited tidal volume ventilation and low driving pressures can often not be achieved [17]. Therefore, adjunctive therapies which allow for less invasive ventilation may be beneficial in ARDS.

Helium is an inert gas with a lower density than air, thus flow of helium through an airway is less turbulent, leading to lower resistance [18]. As a result, during heliox ventilation, lower driving pressures are necessary to distribute oxygen to the distal alveoli to improve oxygenation $[18,19]$. Also, diffusion capacities of $\mathrm{CO}_{2}$ are increased, further resulting in improved gas exchange [18]. Another potential benefit of helium is that it may have anti-inflammatory properties [20]. Helium has been used to reduce the work of breathing during exacerbations of asthma and COPD [19, 21-23]. Most of the data on the effect of heliox have been gathered within these patient populations, whilst most asthma studies have been conducted in the paediatric population. In ARDS, most data on helium ventilation are also derived from the paediatric population, which may be related to an increased airway resistance in neonates and children compared to adults. In light of the increasing awareness of the necessity to limit the intensity of mechanical ventilation $[2,10,13-$ 16], in this descriptive review we investigated whether he- liox has a therapeutic potential in ARDS by summarising the results from preclinical and clinical studies on its use in ARDS.

\section{Methods}

A systematic search of the PubMed and EMBASE databases to identify all publications of studies focusing on the effect of heliox in ARDS was done by the same reviewer. The databases were searched up to January 2014.

The search included search terms referring to the condition ('lung injury'; 'acute lung injury'; 'acute respiratory distress syndrome'; 'ards, human'; 'lung injury'; 'ards'; 'respiratory distress syndrome'; 'respiratory failure'; 'hypoxia'; 'mechanical ventilation'; 'artificial respiration') as well as to the intervention ('helium'; 'heliox'). Retrieved papers were screened for relevance by reading of the abstract by 2 reviewers. The reference lists of selected articles were also screened for additional relevant papers.

Inclusion criteria for article selection of preclinical studies were the use of parameters for animal models of ARDS [24]. Inclusion criteria for the clinical studies were patient populations that were described as having acute respiratory failure with the need for respiratory support (for studies published prior to the existence of the ARDS consensus [25]), or use of the consensus criteria for ARDS [25]. Included titles were limited to the English language.

\section{Results}

Of 576 papers retrieved from PubMed or EMBASE, 556 articles were excluded based on no use of helium during mechanical ventilation, no original data or no ARDS/ acute lung injury condition associated with respiratory failure, leaving 20 papers to be included and described in detail in this review (fig. 1). The level of evidence was graded using the Oxford Centre for Evidence-Based Medicine Levels of Evidence (version 2; http://www. cebm.net/index.aspx? $\mathrm{o}=5653$ ). Risk of bias was not graded due to the descriptive nature of the papers, which also included a series of case reports.

\section{The Effect of Heliox on Lung Mechanics and}

Inflammation in Animal Models of ARDS

We found 3 articles describing the effect of heliox on gas exchange in paediatric animal models and 3 studies using adult animal models.

\section{Neonatal RDS Animal Models}

In a study in neonatal piglets with ARDS induced by saline lavage, animals were ventilated with 40 or $60 \%$ helium balanced with oxygen in a high-frequency oscillatory ventilation (HFOV) mode with fixed mean airway 


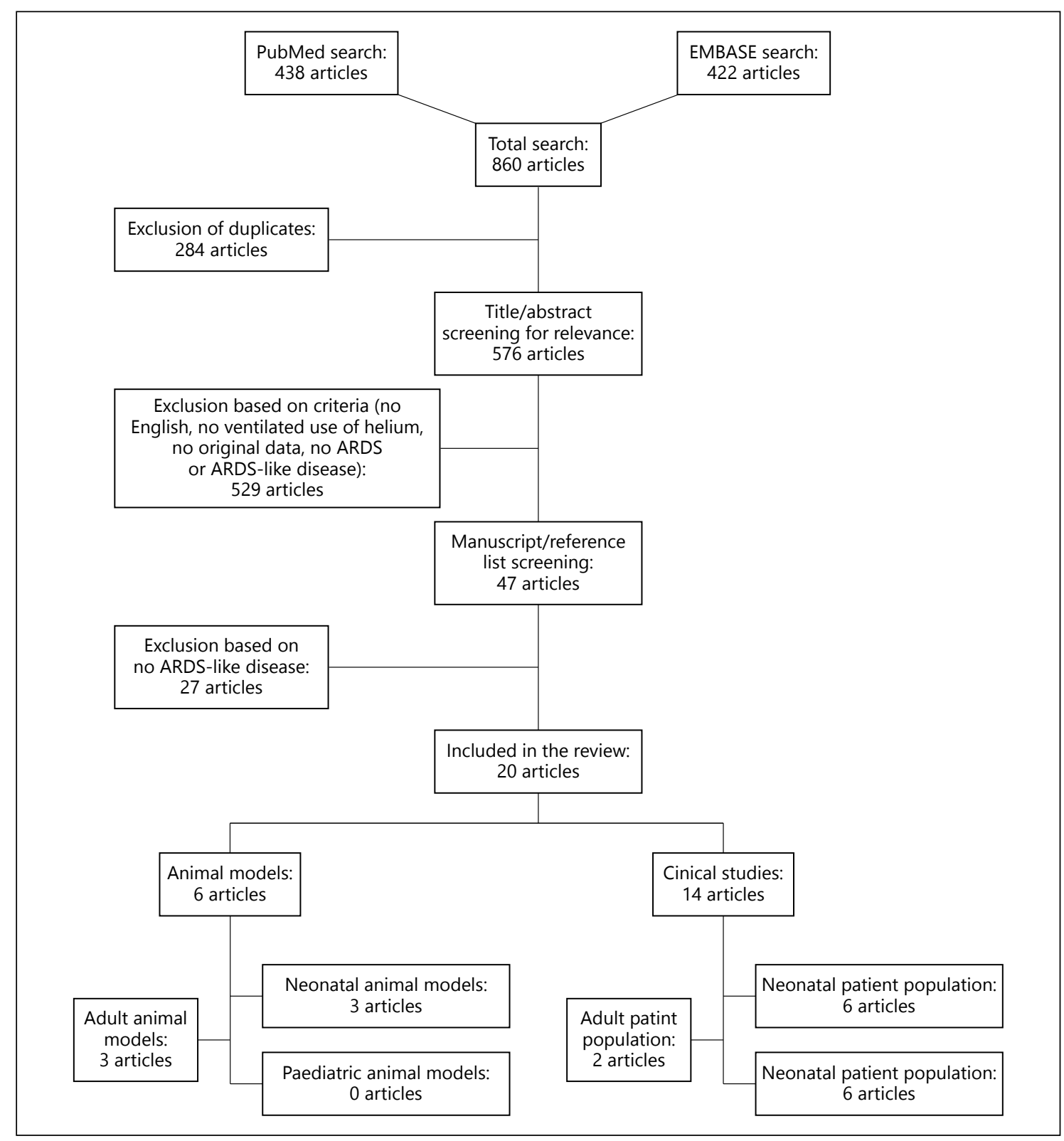

Fig. 1. The study selection process for the inclusion of articles in this review.

pressure, oscillation amplitude and frequency [26]. The ventilation settings were targeted to reach $\mathrm{PaCO}_{2}$ levels of 55-80 $\mathrm{mm} \mathrm{Hg}$ and $\mathrm{PaO}_{2}$ level above $100 \mathrm{~mm} \mathrm{Hg}$. Heliox resulted in decreased $\mathrm{PaCO}_{2}$ levels, combined with a modest improved oxygenation, together with an increased tidal volume delivery, as measured by a pneumotachometer. As increased tidal volume delivery is unwanted in neonatal RDS, the effect of heliox on gas exchange was investigated while keeping the tidal volume constant. Swine with saline lavage-induced ARDS were ventilated with $40 \%$ helium or $40 \%$ nitrogen while tidal volume was kept constant by adjusting the oscillation amplitude [27]. At a constant tidal volume, helium did not alter oxygenation. However, the oscillation amplitude did decrease significantly during heliox ventilation, which relates to a decrease in the peak inspiratory pressure (PIP).

Similar results were found during continuous positive airway pressure (CPAP) ventilation, using a neonatal pig model in which ARDS was induced by oleic acid [28]. Heliox significantly improved gas exchange, reduced the 
need for oxygen and decreased $\mathrm{PaCO}_{2}$ levels compared to animals ventilated with nitrogen. Besides improved gas exchange, heliox ventilation significantly decreased the respiratory rate, tidal volume, minute ventilation and airway resistance, while respiratory compliance increased. Also, heliox improved the amount of aerated lung as measured by histomorphometrical analyses, showing a significantly larger percentage of the gas exchange area relative to the parenchymal area. Interestingly, lung inflammation was also investigated in this model. In the lung tissue of animals ventilated for $4 \mathrm{~h}$, levels of IL- 8 and myeloperoxidase, both indicators of neutrophil activation, were lower in animals ventilated with heliox compared to animals ventilated with nitrogen. Thereby, heliox improved ventilation and reduced barotrauma, resulting in an attenuation of lung inflammation.

In summary, in paediatric animal models of ARDS ventilated in an HFOV mode, heliox improved gas exchange while allowing for less invasive ventilation, with a concomitant reduction in lung inflammation [26-28].

\section{ARDS Animal Models}

In an adult rabbit model of ARDS, lung injury was induced by oleic acid instillation [29]. Animals were ventilated with low bias flow oscillation with a $\mathrm{CO}_{2}$ scrubber, which is a modified HFOV system to reduce gas utilisation. Animals were ventilated in cycles of $20 \mathrm{~min}$, with a variable helium concentration (40-50-60-70\%) balanced with oxygen. All heliox ventilation cycles were preceded by 20 min of ventilation with $40 \%$ oxygen and $60 \%$ nitrogen. After each cycle, a blood gas was drawn. All ventilator settings remained unaltered during the experiment. Ventilation with helium increased $\mathrm{CO}_{2}$ clearance compared to nitrogen-ventilated animals, the magnitude of which correlated with the concentration of helium.

A study in an adult rat model of ARDS induced by saline lavage focused on the effect of helium on histopathological and immunohistochemical changes in lung tissue [30]. Male rats were ventilated in a pressure-controlled mode for $1 \mathrm{~h}$ with either heliox (50\% helium, $50 \%$ oxygen) or $100 \%$ oxygen. After the intervention, rats continued to be ventilated for $2 \mathrm{~h}$ with $50 \%$ oxygen before they were sacrificed and lung tissue was harvested. The severity of pathological features (infiltration of neutrophils, presence of oedema and haemorrhage and hyaline membrane formation) was graded. Heliox ventilation resulted in a reduction of all these features compared to the control group. Also, myeloperoxidase and inducible nitric oxide synthase in lung tissue, which are activated by neutrophils or endothelial cells, respectively, were reduced due to he- liox ventilation. This study suggests a possible role for heliox in attenuating lung inflammation that seems to be unrelated to less invasive mechanical ventilation settings. Of note, however, the control group in this study had hyperoxia, which is known to induce inflammation $[31,32]$.

The effect of heliox on lung mechanics was studied in an adult rat model in which lung injury was provoked by injurious ventilator settings [33]. With tidal volumes of $15 \mathrm{ml} / \mathrm{kg}$, rats were ventilated with either heliox ( $50 \%$ helium, $50 \%$ oxygen) or a standard gas mixture (50\% oxygen, $50 \%$ air) for $4 \mathrm{~h}$, while adjusting the respiratory rate to maintain normocapnia. Heliox ventilation significantly reduced minute volume ventilation, while maintaining a normal acid-base balance and adequate oxygenation. However, pulmonary protein levels and inflammatory cytokine levels were not affected by heliox ventilation.

Taken together, in animal experiments, heliox improved ventilation in ARDS models during pressure-controlled ventilation and spontaneous breathing. However, the effects of heliox on inflammation yield contrasting results $[29,30,33]$.

\section{The Effect of Heliox on Lung Mechanics and Gas \\ Exchange in Clinical Studies}

Clinical studies on the effect of heliox in ARDS patients are limited. We found 14 articles, of which 12 were in the paediatric patient population and 2 in the adult patient population. All trials had small patient numbers, as is shown in table 1 along with the level of evidence for each study.

\section{Neonatal Clinical Studies on RDS}

An important and much referred to study on the effect of helium on gas exchange was performed in premature newborn infants (weight $<2,000 \mathrm{~g}$ ) with neonatal RDS in need of mechanical ventilation before $24 \mathrm{~h}$ of life [34]. In this double-blind randomized study, 31 infants were mechanically ventilated in a volume-controlled mode with either $78 \%$ heliox or nitrox ( $78 \%$ nitrogen, $22 \%$ oxygen) for a maximum of 8 days, after which the ventilator was connected to the standard air-in-oxygen gas mixture again. Mechanical ventilation was targeted to maintain a transcutaneous $\mathrm{PO}_{2}\left(\mathrm{TcPO}_{2}\right)$ between 6 and $9 \mathrm{kPa}$ and $\mathrm{PaCO}_{2}$ levels between 5 and $8 \mathrm{kPa}$. The heliox group showed an improved $\mathrm{TcPO}_{2} / \mathrm{FiO}_{2}$ ratio after 2 days of ventilation compared to the nitrox group. After 4 days of ventilation, mean airway pressure and $\mathrm{FiO}_{2}$ could significantly be reduced in the heliox group compared to the nitrox group. Complications due to neonatal RDS, including bronchopulmonary dysplasia (BPD) and death, were sig- 
Table 1. Overview of clinical studies, with patient numbers and main outcome

\begin{tabular}{|c|c|c|c|c|c|c|}
\hline First author & $\mathrm{n}$ & Study type & Patient population & Ventilation mode & Main outcome & $\begin{array}{l}\text { Level of } \\
\text { evidence }\end{array}$ \\
\hline Elleau [34] & 31 & Randomized controlled trial & ARDS - infant & Volume controlled & $\begin{array}{l}\uparrow \text { Transcutaneous } \\
\mathrm{PO}_{2} / \mathrm{FiO}_{2} \text { ratio }\end{array}$ & $1 b$ \\
\hline Colnaghi [36] & 51 & Randomized controlled trial & ARDS - infant & Nasal CPAP & $\begin{array}{l}\uparrow \mathrm{PaO}_{2} / \mathrm{FiO}_{2} \text { ratio } \\
\downarrow \text { Need for intubation }\end{array}$ & $1 b$ \\
\hline Migliori [37] & 10 & Observational intervention & ARDS - infant & SIMV & $\begin{array}{l}\downarrow \text { Peak inspiratory pressures } \\
\downarrow \text { Work of breathing }\end{array}$ & $2 c$ \\
\hline Szczapa [38] & 8 & Observational intervention & ARDS - infant & SIMV & $\begin{array}{l}\uparrow \mathrm{PaO}_{2} / \mathrm{FiO}_{2} \text { ratio } \\
\downarrow \mathrm{PaCO}_{2} \text { levels }\end{array}$ & $2 c$ \\
\hline Winters [39] & 5 & Case report & ARDS - infant & $\mathrm{HFOV}$ & $\downarrow \mathrm{PaCO}_{2}$ levels & 4 \\
\hline Gross $[40]$ & 10 & Observational intervention & Bronchiolitis - infant & SIMV & $\begin{array}{l}=\mathrm{PaO}_{2} / \mathrm{FiO}_{2} \text { ratio } \\
=\mathrm{PaCO}_{2} \text { levels }\end{array}$ & $2 c$ \\
\hline Kneyber [41] & 13 & Observational intervention & Bronchiolitis - infant & Pressure controlled & $\downarrow$ Airway resistance & $2 c$ \\
\hline Paret [42] & 1 & Case report & Bronchiolitis - infant & $\begin{array}{l}\text { Non-invasive pressure } \\
\text { controlled (head hood) }\end{array}$ & $\downarrow$ Need for intubation & 4 \\
\hline $\begin{array}{l}\text { Martinon-Torres } \\
{[43]}\end{array}$ & 15 & Observational intervention & Bronchiolitis - infant & CPAP & $\begin{array}{l}\downarrow \text { Need for intubation } \\
\downarrow \mathrm{PaCO}_{2} \text { levels }\end{array}$ & $2 c$ \\
\hline Liet $[44]$ & 39 & Randomized controlled trial & Bronchiolitis - infant & $\begin{array}{l}\text { Non-invasive pressure } \\
\text { controlled (head hood) }\end{array}$ & $=$ Need for intubation & $1 \mathrm{~b}$ \\
\hline de Gamarra [46] & 8 & Observational intervention & $\begin{array}{l}\text { Bronchopulmonary } \\
\text { dysplasia - infant }\end{array}$ & $\begin{array}{l}\text { Non-invasive pressure } \\
\text { controlled (Plexiglas chamber) }\end{array}$ & $\downarrow$ Transcutaneous $\mathrm{PO}_{2}$ & $2 c$ \\
\hline Szczapa [47] & 15 & Observational intervention & $\begin{array}{l}\text { Bronchopulmonary } \\
\text { dysplasia - infant }\end{array}$ & Volume controlled & $\uparrow \mathrm{PaO}_{2} / \mathrm{FiO}_{2}$ ratio & $2 c$ \\
\hline Pizov [48] & 7 & Observational intervention & $\begin{array}{l}\text { Respiratory } \\
\text { failure - adult }\end{array}$ & Tracheal insufflation & $\begin{array}{l}\downarrow \mathrm{PaCO}_{2} \text { levels } \\
\downarrow \text { Peak inspiratory pressures }\end{array}$ & $2 c$ \\
\hline Kirby [49] & 2 & Case report & ARDS - adult & $\mathrm{HFOV/BiPAP}$ & $\downarrow \mathrm{PaCO}_{2}$ levels & 4 \\
\hline
\end{tabular}

nificantly higher in the nitrox group. Although the results suggest a beneficial effect of heliox on respiratory status, patient numbers in this study were small. Moreover, this study was carried out before surfactant was introduced as a therapeutic agent in infants with ARDS [35].

The effect of heliox in preterm born infants with neonatal RDS and ventilated with nasal CPAP was investigated in a randomized pilot study [36]. The intervention group $(\mathrm{n}=27)$ received $80 \%$ heliox and the control group $(\mathrm{n}=24)$ received nasal CPAP with medical air. After $12 \mathrm{~h}$, heliox was replaced with medical air if nasal CPAP was still necessary. The main outcome was the requirement of mechanical ventilation within 7 days. Heliox significantly decreased the risk for intubation and need for surfactant therapy. A trend was seen towards improved gas exchange and shortened duration of nasal CPAP in favour of heliox ventilation.
The effect of heliox was studied in 10 preterm infants with neonatal RDS, who received long-term ventilation by synchronised intermittent mandatory ventilation (SIMV) [37]. Heliox (80\% helium, 20\% oxygen) replaced the air-in-oxygen gas mixture. PIPs were adjusted to keep tidal volumes constant. Ventilatory parameters and pulmonary mechanics were measured before, during and after $1 \mathrm{~h}$ of heliox therapy. During heliox ventilation, PIP, $\mathrm{TcPCO}_{2}$ and the work of breathing were reduced, with a concomitant increase in $\mathrm{TcPO}_{2}$ and minute ventilation. Infants who showed a reduction in peak pressures of at least $20 \%$ were extubated. After extubation, they received bilevel positive airway pressure (BiPAP) with heliox for another $3 \mathrm{~h}$. Out of the 10 infants, 8 could be extubated. BiPAP did increase the need for $\mathrm{FiO}_{2}$, but only 1 infant needed re-intubation after $5 \mathrm{~h}$ of ventilation with air-inoxygen. Although the sample size was small and a control 
group was lacking, these results show the ability of heliox to reduce the work of breathing and the need for invasive pressure support ventilation, while improving gas exchange.

In a pilot study in 8 newborns who were mechanically ventilated in a pressure-controlled SIMV mode because of respiratory failure due to meconium aspiration, $80 \%$ heliox was administered for $1 \mathrm{~h} \mathrm{[38].} \mathrm{There} \mathrm{was} \mathrm{a} \mathrm{trend}$ towards increased expiratory tidal volumes, minute ventilation and a peak expiratory flow rate during heliox ventilation. Heliox significantly reduced the alveolar-arterial oxygen tension and increased the $\mathrm{PaO}_{2} / \mathrm{FiO}_{2}$ ratio. Blood gas analysis showed a non-significant decrease in $\mathrm{PaCO}_{2}$ levels with a concomitant increase in $\mathrm{pH}$ values. These beneficial effects of heliox were reversed after ventilation was switched back to an air-in-oxygen gas mixture.

These studies suggest that heliox improves gas exchange and allows for less invasive mechanical ventilation in the neonatal population. Most of the studies had outcomes focussed on lung mechanics, rendering the effect of heliox on clinically relevant outcomes unclear.

Paediatric Clinical Studies on ARDS

A summary of case reports reported the use of HFOV to administer heliox in 5 paediatric intensive care unit patients with hypoxemic respiratory failure and respiratory acidosis, caused by a variety of underlying pathologies [39]. The concentration of helium in the gas mixture differed from 20 to $65 \%$ and exposure time varied from 2 to $6.5 \mathrm{~h}$. Despite this variation, in all patients the $\mathrm{PaCO}_{2}$ levels dropped dramatically after the introduction of heliox compared to nitrogen-oxygen ventilation. Oxygenation remained adequate.

In paediatric patients, ARDS can also be triggered by bronchiolitis, which is caused by the respiratory syncytial virus (RSV). When bronchiolitis is severe, it can result in respiratory failure and the need for respiratory support. In mechanically ventilated children with bronchiolitis, the effect of stepwise increased percentages of helium in the ventilated gas mixture was investigated [40]. Ten infants were ventilated in SIMV mode, with a nitrox gas mixture (50\% nitrogen, 50\% oxygen). During the study protocol, heliox was administered for $15 \mathrm{~min}$ with a concentration of 50,60 or $70 \%$ balanced with oxygen. Gas exchange was measured every $15 \mathrm{~min}$, just before changing the gas mixture. In this setting, heliox did not alter the $\mathrm{PaO}_{2} / \mathrm{FiO}_{2}$ ratio or $\mathrm{PaCO}_{2}$ levels compared to nitrox ventilation. These negative findings were ascribed to the relatively small $\mathrm{CO}_{2}$ retention due to the SIMV mode used, the small sample size, and to a possibly mild-to-moderate lung disease.

In another small study population, 13 infants with RSV infection were ventilated in a pressure-controlled ventilation mode, with $60 \%$ heliox for two periods of $30 \mathrm{~min}$ [41], interspersed with nitrox ventilation $(60 \%$ nitrogen, $40 \%$ oxygen). During ventilation with heliox, the airway resistance was reduced without improving $\mathrm{CO}_{2}$ elimination, PIP or end-expiratory lung volume. The effect on resistance reversed after switching back to nitrox ventilation.

A case report on a 4-month-old boy with RSV-induced bronchiolitis and respiratory failure described the effects of ventilation with $80 \%$ heliox via an oxyhood at 5 litres/ $\min [42]$. In this case, non-invasive heliox therapy avoided intubation and mechanical ventilation, as the respiratory rate and $\mathrm{PaCO}_{2}$ levels dropped dramatically. Heliox therapy was continued for $48 \mathrm{~h}$ before the patient was weaned from the heliox gas mixture.

Non-invasive CPAP ventilation with $70 \%$ heliox has also been used long-term, for up to 14 days in infants with refractory acute bronchiolitis [43]. The clinical condition, oxygenation and gas exchange in 15 paediatric patients admitted to the intensive care unit were measured at baseline and during heliox therapy. Compared to baseline, heliox ventilation improved saturation, the respiratory rate and $\mathrm{PaCO}_{2}$ levels.

These results were not confirmed in a randomized multicentre study in 39 infants investigating the effect of $78 \%$ heliox versus an air-oxygen mix (78\% nitrogen, $22 \%$ oxygen) through a non-invasive inflatable head hood for at least $24 \mathrm{~h} \mathrm{[44]}$. Compared to air-oxygen, heliox did not generate any significant differences in the need for positive-pressure ventilation or gas exchange.

Taken together, the effects of heliox in RSV-induced ARDS are less apparent than in ARDS due to other causes. A possible explanation could be that RSV represents a relatively mild version of ARDS in paediatric patients [45].

\section{Paediatric Clinical Studies on BPD}

Respiratory distress is also common in paediatric patients suffering from BPD, which may be considered a more chronic form of neonatal RDS. The effect of heliox ventilation was studied in 2 groups of 4 neonates with or without BPD [46]. All infants were placed in a Plexiglas chamber, which was filled successively with an air-oxygen mix (78\% nitrogen, $22 \%$ oxygen) and heliox (78\% helium, $22 \%$ oxygen) for a maximum of $3 \mathrm{~h}$. Spontaneous breathing of heliox resulted in acute hypoxia, with sig- 
nificantly decreased $\mathrm{TcPO}_{2}$ levels in the $\mathrm{BPD}$ group versus the control group, whereas $\mathrm{TcPCO}_{2}$ was unaltered. These results limit the application of heliox in patients who are in need of higher oxygen demands.

In another study in 15 patients with respiratory failure due to BPD, $80 \%$ heliox was administered during mechanical ventilation for $1 \mathrm{~h}$ [47]. Compared to baseline, heliox increased the tidal volume, dynamic compliance and peak expiratory flow rate. The $\mathrm{PaO}_{2} / \mathrm{FiO}_{2}$ ratio improved during heliox ventilation, with a related decrease in the alveolar-arterial oxygen tension and oxygenation index. A non-significant decrease was seen in $\mathrm{PaCO}_{2}$ levels, with an increase in $\mathrm{pH}$. All these beneficial effects reversed after switching back to a normal gas mixture.

In summary, these clinical studies in paediatric patients suggest that heliox ventilation reduces the work of breathing and the need for mechanical ventilation, with the clearest effect in ARDS and least effect in RSV-induced respiratory failure. Due to small samples sizes, results were often non-significant.

\section{Adult Clinical Studies on ARDS}

Clinical studies of the effect of heliox in adult patients with ARDS are scarce. To reduce hypercapnia, tracheal gas insufflation with $100 \%$ oxygen or $100 \%$ helium was investigated in 7 mechanically ventilated patients with respiratory failure due to various aetiologies [48]. Tracheal insufflation was administered at 2, 4 and 6 litres/min for 15 min. Heliox decreased $\mathrm{PaCO}_{2}$ levels with both gases. Compared to baseline, the maximum flow of helium resulted in a decrease in PIP. Overall, the efficiency of tracheal insufflation, calculated by dividing the $\mathrm{PaCO}_{2}$ change by the change in PIP, improved with the use of helium.

In a summary of 2 case reports of patients with bronchiolitis obliterans syndrome and acute respiratory failure following lung transplantation, $60 \%$ heliox was administered either via BiPAP or HFOV [49]. Heliox ventilation increased $\mathrm{pH}$ and decreased $\mathrm{PaCO}_{2}$ levels, and therefore respiratory status was improved.

\section{Safety of Heliox Ventilation}

There is extensive experience with heliox in asthma and COPD patients, and complications have not been reported [21, 50-55]. The lower density of helium causes inaccurately high readings from flow meters calibrated for air and/or oxygen $[18,22]$. Therefore, the flow transducer within the ventilator needs adjustment to correctly measure the flow in order to prevent a discrepancy in used tidal volumes and a misinterpreted improvement in $\mathrm{CO}_{2}$ clearance.

The safety of heliox during mechanical ventilation in patients with acute respiratory failure is rarely described [23]. In paediatric patients, the frequency of complications was described, without any appreciable effect of heliox ventilation [34]. Another case report describes that heliox ventilation was safe during pregnancy [56]. It is of note, however, that the safety of heliox in various modes of ventilation has not been studied systematically.

The percentage of oxygen within the heliox mixture is a concern when ventilating severely hypoxic ARDS patients. The efficacy of heliox is proportional to the percentage used, which may not allow for sufficient $\mathrm{FiO}_{2}$ in hypoxic patients. Of note, however, adverse outcome in ARDS may be more related to causes other than hypoxemia, including multiple organ failure and right ventricular failure.

\section{Discussion and Conclusion}

In general, both preclinical and clinical studies showed improved ventilation and gas exchange with heliox ventilation. Neonatal RDS animal models mostly used HFOV, in which heliox improved gas exchange while allowing for less invasive ventilation, with an associated decrease in lung inflammation. In adult animal ARDS models, heliox improved ventilation during both pressurecontrolled ventilation and spontaneous breathing. The effects of heliox on inflammation show contrasting results, raising the question of whether heliox decreases inflammation by reducing the intensity of ventilation or if it also has a direct anti-inflammatory effect.

The effects of heliox on the intensity of mechanical ventilation are expected immediately following the application of heliox ventilation. In line with this, all clinical studies on ARDS showed promising effects of heliox on short-term outcomes, including minute volume ventilation, applied pressures and in most studies also gas exchange. In the paediatric patient studies, heliox ventilation was also found to influence relevant clinical outcomes, including reduced work of breathing and need for mechanical ventilation. In the adult clinical studies, heliox long-term outcomes have not been investigated.

Small patient numbers, differences in study designs, the aetiology of ARDS, the lack of original data and in the quality of the papers limit the interpretation of the existing data. Also, the effects of heliox in asthma and COPD are likely to be different to the effects in ARDS, which is 
a limitation of this review. Also, it is clear that data on relevant outcome parameters are scarce. Therefore, any formal grading at this point seems inappropriate. We conclude that the summarized evidence in this review suggests that heliox improves gas exchange and may reduce the intensity of mechanical ventilation in ARDS on a short-term basis. However, data on clinical outcome are limited.

\section{Acknowledgements}

This work was supported by an NWO ZonMW Clinical Fellowship to Dr. N.P. Juffermans (project number: 90700269).

\section{Financial Disclosure and Conflicts of Interest}

\section{References}

1 MacCallum NS, Evans TW: Epidemiology of acute lung injury. Curr Opin Crit Care 2005; 11:43-49.

-2 Villar J, Blanco J, Anon JM, Santos-Bouza A, Blanch L, Ambros A, Gandia F, Carriedo D, Mosteiro F, Basaldua S, et al: The ALIEN study: incidence and outcome of acute respiratory distress syndrome in the era of lung protective ventilation. Intensive Care Med 2011;37:1932-1941.

- 3 Zimmerman JJ, Akhtar SR, Caldwell E, Rubenfeld GD: Incidence and outcomes of pediatric acute lung injury. Pediatrics 2009;124:87-95.

$\checkmark 4$ Ashbaugh DG, Bigelow DB, Petty TL, Levine BE: Acute respiratory distress in adults. Lancet 1967;2:319-323.

5 Wright PE, Bernard GR: The role of airflow resistance in patients with the adult respiratory distress syndrome. Am Rev Respir Dis 1989;139:1169-1174.

6 Pelosi P, Cereda M, Foti G, Giacomini M, Pesenti A: Alterations of lung and chest wall mechanics in patients with acute lung injury: effects of positive end-expiratory pressure. Am J Respir Crit Care Med 1995;152:531-537.

7 Clark RH, Gerstmann DR, Jobe AH, Moffitt ST, Slutsky AS, Yoder BA: Lung injury in neonates: causes, strategies for prevention, and long-term consequences. J Pediatr 2001;139: 478-486.

8 Fraser J, Walls M, McGuire W: Respiratory complications of preterm birth. BMJ 2004; 329:962-965.

-9 Belperio JA, Keane MP, Lynch JP 3rd, Strieter $\mathrm{RM}$ : The role of cytokines during the pathogenesis of ventilator-associated and ventilator-induced lung injury. Semin Respir Crit Care Med 2006;27:350-364.

10 Bellani G, Guerra L, Musch G, Zanella A, Patroniti N, Mauri T, Messa C, Pesenti A: Lung regional metabolic activity and gas volume changes induced by tidal ventilation in patients with acute lung injury. Am J Respir Crit Care Med 2011;183:1193-1199.

11 Slutsky AS, Ranieri VM: Ventilator-induced lung injury. N Engl J Med 2013;369:2126 2136.

12 Haitsma JJ, Schultz MJ, Hofstra JJ, Kuiper JW, Juco J, Vaschetto R, Levi M, Zhang H, Slutsky AS: Ventilator-induced coagulopathy in ex- perimental Streptococcus pneumoniae pneumonia. Eur Respir J 2008;32:1599-1606.

13 The ARDS Network: Ventilation with lower tidal volumes as compared with traditional tidal volumes for acute lung injury and the acute respiratory distress syndrome. $\mathrm{N}$ Engl Med 2000;342:1301-1308.

14 Bein T, Weber-Carstens S, Goldmann A, Muller T, Staudinger T, Brederlau J, Muellenbach R, Dembinski R, Graf BM, Wewalka M, et al: Lower tidal volume strategy $(\approx 3 \mathrm{ml} / \mathrm{kg})$ combined with extracorporeal $\mathrm{CO}_{2}$ removal versus 'conventional' protective ventilation $(6 \mathrm{ml} / \mathrm{kg})$ in severe ARDS. Intensive Care Med 2013;39:847-856.

15 Amato MB, Barbas CS, Medeiros DM, Magaldi RB, Schettino GP, Lorenzi-Filho G, Kairalla RA, Deheinzelin D, Munoz C, Oliveira R, et al: Effect of a protective-ventilation strategy on mortality in the acute respiratory distress syndrome. N Engl J Med 1998;338:347-354.

16 Estenssoro E, Dubin A, Laffaire E, Canales H, Saenz G, Moseinco M, Pozo M, Gomez A, Baredes N, Jannello G, et al: Incidence, clinical course, and outcome in 217 patients with acute respiratory distress syndrome. Crit Care Med 2002;30:2450-2456.

17 Kumar A, Zarychanski R, Pinto R, Cook DJ, Marshall J, Lacroix J, Stelfox T, Bagshaw S, Choong K, Lamontagne F, et al: Critically ill patients with 2009 influenza $\mathrm{A}(\mathrm{H} 1 \mathrm{~N} 1)$ infection in Canada. JAMA 2009;302:1872-1879.

18 Hess DR, Fink JB, Venkataraman ST, Kim IK, Myers TR, Tano BD: The history and physics of heliox. Respir Care 2006;51:608-612.

19 Gentile MA: Inhaled medical gases: more to breathe than oxygen. Respir Care 2011;56: 1341-1359.

20 Oei GT, Weber NC, Hollmann MW, Preckel B: Cellular effects of helium in different organs. Anesthesiology 2010;112:1503-1510.

21 Myers TR: Use of heliox in children. Respir 33 Care 2006;51:619-631.

22 Venkataraman ST: Heliox during mechanical ventilation. Respir Care 2006;51:632-639.

23 Gainnier M, Forel JM: Clinical review: use of helium-oxygen in critically ill patients. Crit Care 2006; 10:241.

24 Matute-Bello G, Downey G, Moore BB, Groshong SD, Matthay MA, Slutsky AS, Kuebler
WM: An official American Thoracic Society workshop report: features and measurements of experimental acute lung injury in animals. Am J Respir Cell Mol Biol 2011;44:725-738.

25 The ARDS Definition Task Force: Acute respiratory distress syndrome: the Berlin Definition. JAMA 2012;307:2526-2533.

26 Katz A, Gentile MA, Craig DM, Quick G, Meliones JN, Cheifetz IM: Heliox improves gas exchange during high-frequency ventilation in a pediatric model of acute lung injury. Am J Respir Crit Care Med 2001;164:260-264.

27 Katz AL, Gentile MA, Craig DM, Quick G, Cheifetz IM: Heliox does not affect gas exchange during high-frequency oscillatory ventilation if tidal volume is held constant. Crit Care Med 2003;31:2006-2009.

28 Nawab US, Touch SM, Irwin-Sherman T, Blackson TJ, Greenspan JS, Zhu G, Shaffer TH, Wolfson MR: Heliox attenuates lung inflammation and structural alterations in acute lung injury. Pediatr Pulmonol 2005;40:524532.

29 Siddappa R, Dowhy MS, Rotta AT, Hernan LJ, Fuhrman BP: Low bias flow oscillation with heliox in oleic acid-induced lung injury. Pediatr Crit Care Med 2005;6:70-75.

30 Yilmaz S, Daglioglu K, Yildizdas D, Bayram I, Gumurdulu D, Polat S: The effectiveness of heliox in acute respiratory distress syndrome. Ann Thorac Med 2013;8:46-52.

31 Nagato A, Silva FL, Silva AR, Bezerra FS, Oliveira ML, Bello-Klein A, Cristovao Porto L, Santos Valenca S: Hyperoxia-induced lung injury is dose dependent in Wistar rats. Exp Lung Res 2009;35:713-728.

- 32 Sinclair SE, Altemeier WA, Matute-Bello G, Chi EY: Augmented lung injury due to interaction between hyperoxia and mechanical ventilation. Crit Care Med 2004;32:24962501.

33 Beurskens CJ, Aslami H, de Beer FM, Vroom MB, Preckel B, Horn J, Juffermans NP: Heliox allows for lower minute volume ventilation in an animal model of ventilator-induced lung injury. PLoS One 2013;8:e78159.

-34 Elleau C, Galperine RI, Guenard H, Demarquez JL: Helium-oxygen mixture in respiratory distress syndrome: a double-blind study. J Pediatr 1993;122:132-136. 
35 Recommendations for neonatal surfactant therapy. Paediatr Child Health 2005;10:109116.

36 Colnaghi M, Pierro M, Migliori C, Ciralli F, Matassa PG, Vendettuoli V, Mercadante D, Consonni D, Mosca F: Nasal continuous positive airway pressure with heliox in preterm infants with respiratory distress syndrome. Pediatrics 2012;129:e333-e338.

37 Migliori C, Gancia P, Garzoli E, Spinoni V, Chirico G: The effects of helium/oxygen mixture (heliox) before and after extubation in long-term mechanically ventilated very low birth weight infants. Pediatrics 2009;123: 1524-1528.

$>38$ Szczapa T, Gadzinowski J: Use of heliox in the management of neonates with meconium aspiration syndrome. Neonatology 2011;100: 265-270.

$>39$ Winters JW, Willing MA, Sanfilippo D: Heliox improves ventilation during high-frequency oscillatory ventilation in pediatric patients. Pediatr Crit Care Med 2000;1:33-37.

40 Gross MF, Spear RM, Peterson BM: Heliumoxygen mixture does not improve gas exchange in mechanically ventilated children with bronchiolitis. Crit Care 2000;4:188-192.

-41 Kneyber MC, van Heerde M, Twisk JW, Plotz FB, Markhors DG: Heliox reduces respiratory system resistance in respiratory syncytial virus induced respiratory failure. Crit Care 2009; 13:R71.

-42 Paret G, Dekel B, Vardi A, Szeinberg A, Lotan D, Barzilay Z: Heliox in respiratory failure secondary to bronchiolitis: a new therapy. Pediatr Pulmonol 1996;22:322-323.
43 Martinon-Torres F, Rodriguez-Nunez A, Martinon-Sanchez JM: Nasal continuous positive airway pressure with heliox in infants with acute bronchiolitis. Respir Med 2006; 100:1458-1462.

44 Liet JM, Millotte B, Tucci M, Laflammme S, Hutchison J, Creery D, Ducruet T, Lacroix J: Noninvasive therapy with helium-oxygen for severe bronchiolitis. J Pediatr 2005;147:812817.

45 Hammer J, Numa A, Newth CJ: Acute respiratory distress syndrome caused by respiratory syncytial virus. Pediatr Pulmonol 1997; 23:176-183.

46 de Gamarra E, Moriette G, Farhat M, Walti H: Heliox tolerance in spontaneously breathing neonates with bronchopulmonary dysplasia. Biol Neonate 1998;74:193-199.

47 Szczapa T, Gadzinowski J, Moczko J, Merritt TA: Heliox for mechanically ventilated newborns with bronchopulmonary dysplasia. Arch Dis Child Fetal Neonatal Ed 2014;99: F128-F133.

48 Pizov R, Oppenheim A, Eidelman LA, Weiss YG, Sprung CL, Cotev S: Helium versus oxygen for tracheal gas insufflation during mechanical ventilation. Crit Care Med 1998;26: 290-295.

49 Kirkby S, Robertson M, Evans L, Preston TJ, Tobias JD, Galantowicz ME, McKee CT, Hayes D Jr: Helium-oxygen mixture to facilitate ventilation in patients with bronchiolitis obliterans syndrome after lung transplantation. Respir Care 2013;58:e42-e46.
50 Gainnier M, Arnal JM, Gerbeaux P, Donati S, Papazian L, Sainty JM: Helium-oxygen reduces work of breathing in mechanically ventilated patients with chronic obstructive pulmonary disease. Intensive Care Med 2003;29: 1666-1670.

51 Jolliet P, Watremez C, Roeseler J, Ngengiyumva JC, de Kock M, Clerbaux T, Tassaux D, Reynaert M, Detry B, Liistro G: Comparative effects of helium-oxygen and external positive endexpiratory pressure on respiratory mechanics, gas exchange, and ventilation-perfusion relationships in mechanically ventilated patients with chronic obstructive pulmonary disease. Intensive Care Med 2003;29:1442-1450.

52 Tassaux D, Jolliet P, Roeseler J, Chevrolet JC: Effects of helium-oxygen on intrinsic positive end-expiratory pressure in intubated and mechanically ventilated patients with severe chronic obstructive pulmonary disease. Crit Care Med 2000;28:2721-2728.

53 Frazier MD, Cheifetz IM: The role of heliox in paediatric respiratory disease. Paediatr Respir Rev 2010;11:46-53.

54 Gluck EH, Onorato DJ, Castriotta R: Heliumoxygen mixtures in intubated patients with status asthmaticus and respiratory acidosis. Chest 1990;98:693-698.

55 Gupta VK, Cheifetz IM: Heliox administration in the pediatric intensive care unit: an evidence-based review. Pediatr Crit Care Med 2005;6:204-211.

56 George R, Berkenbosch JW, Fraser RF 2nd, Tobias JD: Mechanical ventilation during pregnancy using a helium-oxygen mixture in a patient with respiratory failure due to status asthmaticus. J Perinatol 2001;21:395-398. 